\title{
Medication adherence in patients with schizophrenia: a qualitative study of the patient process in motivational interviewing
}

Jos Dobber ${ }^{1 *} \mathbb{D}$, Corine Latour ${ }^{1}$, Lieuwe de Haan², Wilma Scholte op Reimer ${ }^{1,3}$, Ron Peters ${ }^{3}$, Emile Barkhof $^{4}$ and Berno van Meijel $\left.\right|^{5,6,7}$

\begin{abstract}
Background: Motivational interviewing (MI) may be an effective intervention to improve medication adherence in patients with schizophrenia. However, for this patient group, mixed results have been found in randomized controlled trials. Furthermore, the process of becoming (more) motivated for long-term medication adherence in patients with schizophrenia is largely unexplored.

Method: We performed a qualitative multiple case study of Ml-sessions to analyse the interaction process affecting motivation in patients with schizophrenia. Fourteen cases of patients with schizophrenia, who recently experienced a psychotic relapse after medication-nonadherence, were studied, comprising 66 audio-recorded Ml-sessions. In the Ml-sessions, the patients expressed their cognitions on medication. We used these cognitions to detect the different courses (or patterns) of the patients' ambivalence during the Ml-intervention. We distinguished successful and unsuccessful cases, and used the cross-case-analysis to identify success factors to reach positive effects of MI.

Results: Based on the expressed cognitions on medication, we found four different patterns of the patient process. We also found three success factors for the intervention, which were a trusting relationship between patient and therapist, the therapist's ability to adapt his MI-strategy to the patient's process, and relating patient values to long-term medication adherence.
\end{abstract}

Conclusions: The success of an Ml-intervention for medication adherence in patients with schizophrenia can be explained by well-defined success factors. Adherence may improve if therapists consider these factors during Ml-sessions.

Keywords: Motivational interviewing, Schizophrenia, Medication-adherence, Patient process

\section{Background}

About $75 \%$ of patients with schizophrenia discontinue their antipsychotic drug treatment within 18 months [1]. Antipsychotic drug treatment reduces the risk of relapse $(\mathrm{RR}=.35)$, and the risk of readmission $(\mathrm{RR}=.38)[2]$. It also increases the risks of a movement disorder $(R R=1$. $55)$, sedation $(R R=1.50)$, and weight gain $(R R=2.07)$ [2]. In a systematic review, Higashi et al. [3] found that

\footnotetext{
* Correspondence: j.t.p.dobber@hva.nl

${ }^{1}$ ACHIEVE Centre of Applied Research, Faculty of Health, Amsterdam University of Applied Sciences, Tafelbergweg 51, 1105 BD Amsterdam, The Netherlands

Full list of author information is available at the end of the article
}

lack of illness insight, beliefs about the effectiveness of medication, substance abuse, and the quality of the therapeutic relationship were important influencing factors. Enhancing patient motivation, by taking into account these factors, may be key to encouraging medication adherence.

Motivational Interviewing (MI) is an effective intervention to enhance motivation for behavioural change [4-8]. MI has been investigated as an intervention for medication adherence problems in patients with psychotic disorders. Although the results are mixed, MI shows promising results in several studies [9-12].

(c) The Author(s). 2018 Open Access This article is distributed under the terms of the Creative Commons Attribution 4.0 International License (http://creativecommons.org/licenses/by/4.0/), which permits unrestricted use, distribution, and 
MI-interventions comprise four overlapping processes: engaging (establishing a trusting relationship), focusing (determining the target behaviour for change), evoking (eliciting patients' own good motives in favour of change: "change talk"), and planning (helping to move on to actual change) [13]. In MI-theory three critical components of motivation comprise (1) willingness/importance, (2) ability/confidence and (3) readiness to change [14]. Patients are often ambivalent, expressing conflicting motivations towards change. Supporting the patient to solve this ambivalence is an important task of the MI-therapist [13]. When applying MI, therapists intentionally influence these components to elicit intrinsic motivation and to enable behavioural change. Hereto the therapist communicates in an empathic style and with "MI-Spirit" (the core values of MI: partnership, acceptance, evocation and compassion) [13]. The "language of change" plays a major role in MI. MItherapists elicit patient change talk in which the patient hears her/himself argue for change. Meanwhile therapists try to avoid "patient sustain talk" (in favour of status quo). To be effective, the therapist tunes the MIstrategy to the patient's process of becoming more motivated. Specific knowledge of the nature of this process in patients with schizophrenia may help practitioners to improve their tuning of the motivational process in the MI-sessions and enhance the effects of MI for sustained medication adherence. Therefore, the aim of this current study is to explore the patient process of becoming (more) motivated in a group of patients with schizophrenia, who recently experienced a psychotic relapse after medication-nonadherence. We address the following questions: (1) Can different patterns of the patient process be distinguished in patients with schizophrenia? (2) Can successful cases be distinguished from unsuccessful cases? (3) How do successful cases differ from unsuccessful cases?

\section{Methods \\ Study design}

We used a qualitative multiple case study [15] to discover and explore the patient's motivational process during MIsessions. This design is an inductive interpretative study of cases, to promote understanding of psychosocial processes influencing the patient process of becoming motivated for long-term medication use.

The multiple case study analysis comprised three phases: single case analysis, cross case analysis, and cross case synthesis [15]. Each case consisted of (1) audio records of at least three MI-sessions, (2) coded transcripts, (3) global ratings of the therapist style and the patient self-exploration in each session, and (4) summary scores measuring therapist MI-fidelity.

\section{Study population}

The cases were derived from the intervention group of a Randomized Controlled Trial investigating the effect of MI on medication adherence in non-adherent patients with multi-episode schizophrenia, who had experienced a recent psychotic relapse, following nonadherence to antipsychotic treatment [9]. The 55 participants in the intervention group were offered up to nine MI-sessions to promote motivation for medication-adherence.

\section{Data collection and analysis}

In the original trial, MI-sessions were audio-recorded if the participant consented to this. In the present study, patients were included if there were at least three sessions audiotaped, and if the patient did not experience active psychotic symptoms (as demonstrated by dominant verbal references to current hallucinations or delusions) during the MI-intervention. Five therapists were involved: a psychiatrist, a psychologist, and three community mental health nurses. Neither of the therapists had previous experience in MI. They followed a 32-h MI training by a certified MI-trainer (member of the Motivational Interviewing Network of Trainers), and participated in monthly supervision on MI-fidelity during the conduct of the trial.

All audio recordings were transcribed verbatim, and parsed into patient and therapist utterances. For coding, we used a combination of the Motivational Interviewing Sequential Code for Observing Process Exchanges (SCOPE) [16] and the Motivational Interviewing Skill Code 2.1 (MISC 2.1) [17] (Table 1). For each session, summary scores were computed to assess the quality of MI-execution [16-18]. The first author was trained in MISC-coding at the MI-coding lab of the Center for Alcohol and Addiction Studies, Brown University, USA. He subsequently trained the two coders (one master level, one bachelor level) for performing data-analysis in the present study. After a 37-h training the coders reached a Kappa of .82 on behaviour codes. For the global ratings, we considered a maximum of one point difference on the 7-point scales as an agreement, and a difference of more than one point as a disagreement. So, we dichotomised the scores to "agreement" and "disagreement" (see also Kaplan et al. [19]). After the training, the coders reached a Kappa of 1.0 on the global ratings. Transcripts were first broken down into separate encodable utterances ("parses") by one coder. A second coder then coded the transcript in two passes. In the first pass, the coder listened uninterruptedly to the complete session, assigned the global ratings, and registered the optional MI-components (Table 1). In the second pass, each parse was coded in one of the coding categories (Table 1). Coding dilemmas were solved in weekly coder-trainer meetings. We randomly selected $10 \%(n=7)$ of the sessions for recoding by the same coder to verify intra-rater agreement (Kappa behaviour 
Table 1 Measures and coding instruments

\begin{tabular}{|c|c|c|}
\hline $\begin{array}{l}\text { Unit of } \\
\text { measurement }\end{array}$ & Measurement & Coding instrument \\
\hline \multirow[t]{4}{*}{ Therapist } & $\begin{array}{l}\text { sequential coding of } 20 \text { verbal behaviours: question, reflection, advice with } \\
\text { permission, permission seeking, affirm, emphasize control, support, advice } \\
\text { without permission, confront, direct, opinion, raise concern, warn, facilitate, } \\
\text { feedback, filler, self-disclosure, general information, structure, not encodable. }\end{array}$ & $\begin{array}{l}\text { SCOPE (Motivational Interviewing Sequentia } \\
\text { Code for Observing Process Exchanges) [16] }\end{array}$ \\
\hline & $\begin{array}{l}\text { rating of } 5 \mathrm{Ml} \text {-core values and other relational ingredients on a 7-point } \\
\text { global rating scale: acceptance, empathy, collaboration, evocation, autonomy. }\end{array}$ & $\begin{array}{l}\text { MISC } 2.1 \text { (Motivational Interviewing Skill } \\
\text { Code) [17] }\end{array}$ \\
\hline & $\begin{array}{l}\text { computing } 5 \text { summary scores: } \\
\text { - ratio of reflections to questions, } \\
\text { - percent open questions, } \\
\text { - percent complex reflections, } \\
\text { - percent Ml-consistent techniques, } \\
\text { - mean global ratings. }\end{array}$ & $\begin{array}{l}\text { MITI 3.1.1 (Motivational Interviewing } \\
\text { Treatment Integrity) [18] } \\
\text { SCOPE } \\
\text { SCOPE } \\
\text { SCOPE } \\
\text { SCOPE } \\
\text { MISC } 2.1\end{array}$ \\
\hline & $\begin{array}{l}\text { registration of optional Ml-components: decisional balance, importance ruler, } \\
\text { confidence ruler, typical day/week, looking back, looking forward, exploring } \\
\text { goals and values, querying extremes, developing change plan. }\end{array}$ & Registration: applied / not applied \\
\hline \multirow[t]{3}{*}{ Patient } & $\begin{array}{l}\text { sequential coding of } 10 \text { patient verbal behaviours: commitment, desire, ability, } \\
\text { reasons, need, taking steps, other, ask, follow neutral, not encodable. }\end{array}$ & SCOPE \\
\hline & rating of the level of patient self-exploration on a 7-point global rating scale. & MISC 2.1 \\
\hline & percent patient change talk. & SCOPE \\
\hline
\end{tabular}

codes $=.77$; Kappa global ratings $=1.0$ ), and $20 \%$ of the sessions $(n=13)$, randomly selected, were double-coded for interrater agreement (Kappa behaviour codes $=.71$; Kappa global ratings $=.84$ ).

During the multiple case analysis, a detailed log was kept on the research process, the findings, and the decisions. The analyst (JD) used worksheets based on Stake [15] to structure the analysis, and composed case reports. Two other investigators (CL, BvM) independently scrutinized random subsets of these materials, to ascertain the appropriateness of the research process, and to assure the integrity of the findings, decisions, and conclusions. Also, another investigator independently double analysed two cases. In case of disagreement, the original data were checked and disagreements were resolved by discussion.

\section{Measurement of the motivational process}

We considered shifts in the cognitions on medication during the MI-sessions as indicative for changes in the patient process of motivation for long-term medication adherence. The course of these cognitions during the MI-sessions was used to determine the pattern of the patient motivational process. We assumed that a trusting relationship between patient and therapist supports the patient to open up and talk freely about his/her experiences, goals, values, concerns and ambivalence related to medication adherence. This patient self-exploration is measured by a 7-point global rating scale [17]. We regarded a score of four or higher on this scale as an indication of a trusting relationship.
We deduced criteria to distinguish successful and unsuccessful cases from the aim of the MI-intervention in the original study, i.e. to enhance motivation for long-term medication adherence [9]. In this intervention, the therapist should support the patient to find and explore his/her reasons and motives for medication use, and help to relate medication adherence to the patient's values and goals. If at baseline the patient felt ambivalent about his/her long-term medication, the patient and therapist should explore this ambivalence, and, if appropriate, potential barriers. Hence, the patient may be able to solve the ambivalence or may find ways to handle perceived barriers in relation to medication adherence, based on intrinsic motivation. If the patient is not ambivalent, but takes a convinced position pro or against long-term medication use, the intervention should concentrate on either potential barriers and strengthening long-term motivation for medication adherence (in case of a motivated patient), or exploring possible goals and values in relation to medication adherence to find out if new perspectives on medication adherence can be evoked (in case of no motivation). Thus, three criteria for success applied to all cases, while other criteria depended on the baseline ambivalence and motivation (Table 2).

Finally, we compared the determined patient motivational processes with the outcomes on the medication adherence item of the Life Chart Score [20] (LCS, range 1-5, higher scores indicating higher levels of adherence) in the original RCT at 6-month follow-up [9]. 
Table 2 Criteria for success

\begin{tabular}{|c|c|c|c|}
\hline \multirow[t]{2}{*}{ Criteria } & \multirow{2}{*}{$\begin{array}{l}\text { Ambivalent } \\
\text { at baseline }\end{array}$} & \multicolumn{2}{|c|}{ Not ambivalent at baseline } \\
\hline & & $\begin{array}{l}\text { motivated } \\
\text { for } M A^{a}\end{array}$ & $\begin{array}{l}\text { no motivation } \\
\text { for } \mathrm{MA}^{\mathrm{a}}\end{array}$ \\
\hline $\begin{array}{l}\text { During the Ml-sessions the patient has seriously considered what his/her motives are (not) to } \\
\text { adhere to long-term medication. }\end{array}$ & $x$ & $x$ & $x$ \\
\hline Existing ambivalence and/or potential barriers are explored. & $x$ & $x^{b}$ & \\
\hline Values and goals are explicitly discussed in relation to medication adherence. & $x$ & $x$ & $x$ \\
\hline The patient solved the ambivalence and/or has an action plan for perceived barriers. & $x$ & & \\
\hline Long-term motivation was strengthened. & & $x$ & \\
\hline $\begin{array}{l}\text { The decision (not) to adhere is based on intrinsic motivation: the patient articulates the intention } \\
\text { (not) to adhere to long-term medication, based on motives that are valid to the patient. }\end{array}$ & $x$ & $x$ & $x$ \\
\hline
\end{tabular}

${ }^{\mathrm{a}} \mathrm{MA}=$ Medication adherence

${ }^{\mathrm{b}}$ Exploration of potential barriers

\section{Results}

The inclusion criteria led to a sample consisting of 66 audiotaped sessions of 14 of the 55 participants of the original trial. The participants' background characteristics are listed in Table 3. Based on MI-theory, we

Table 3 Background characteristics

\begin{tabular}{ll}
\hline & Number (\%) $n=$ \\
\hline Gender: male & 14 \\
Age: mean (range) & $10(71 \%)$ \\
$21-30$ & $35.5(23-48)$ \\
$31-40$ & $4(28.5 \%)$ \\
$41-50$ & $6(43 \%)$ \\
Ethnicity & $4(28.5 \%)$ \\
Dutch & \\
Surinamese & $6(43 \%)$ \\
African & $4(28.5 \%)$ \\
Asian & $3(21.5 \%)$ \\
Native language is Dutch & $1(7 \%)$ \\
Yes & \\
No & 9 \\
Highest education & 5 \\
primary education or less & \\
secondary education & \\
tertiary/further education & \\
Duration of illness: mean in years (range) & \\
Number of prior psychiatric admissions: mean \\
(range)
\end{tabular}

distinguished eight possible patterns of the patient process (Table 4).

All patients expressed cognitions on medication use. Overall, 213 cognitions were classified in four categories: (1) cognitions supporting motivation for long-term medication use $(n=90)$; (2) cognitions containing reasons to stop $(n=58)$; (3) cognitions reflecting doubt or ambivalence $(n=19)$; and (4) other cognitions $(n=46)$. Based on the course of the expressed cognitions during the MI-sessions, we detected four of eight theorized patterns of the patient process of becoming motivated (Table 4). In one case, we were not able to detect a pattern because the patient avoided serious conversations regarding medication adherence. Four cases followed the pattern 'Ambivalent - not solved'. In the nine other cases, the patient was not ambivalent (six cases) or resolved his/her ambivalence during the MI-sessions (three cases).

Based on the criteria, we considered four cases to have run through 'a successful patient process' (Table 5). Hereafter we first discuss the similarities and differences between the four patient processes that we observed, and next we discuss the characteristics of the successful and unsuccessful cases.

\section{Pattern 1: Not ambivalent, motivated for medication adherence}

In this pattern, the four patients (cases 9, 10, 11 and 12) have in common that, from the start of the intervention, they expressed cognitions that support motivation for long-term medication use (Table 6a). So, at first glance, they don't seem to need the MI-intervention. However, the task of the MI-therapist is also to maintain and strengthen motivation and explore potential barriers. This only happened in case 10 (successful case), where the therapist guided the patient to explain how he stays in control, and how medication helps him "to have a better life". The patient stressed the value of this argument for medication adherence: "even if I'll have to use 
Table 4 Patterns of the patient process

\begin{tabular}{|c|c|c|c|c|}
\hline \multirow{2}{*}{$\frac{\text { Baseline }}{\text { Not-ambivalent }}$} & \multicolumn{3}{|c|}{ Development of patient process during Ml-sessions } & \multirow{2}{*}{$\begin{array}{l}\text { Observed cases in this pattern } \\
\text { cases } 9,10,11,12\end{array}$} \\
\hline & Remained not-ambivalent & & Motivation for medication adherence & \\
\hline & & & No motivation for medication adherence & cases 3 and 7 \\
\hline & Became ambivalent & Ambivalence, solved & Motivation for medication adherence & no cases \\
\hline & & & No motivation for medication adherence & no cases \\
\hline & & Ambivalence, not solved & & no cases \\
\hline \multirow[t]{3}{*}{ Ambivalent } & & Ambivalence, solved & Motivation for medication adherence & cases $5,13,14$ \\
\hline & & & No motivation for medication adherence & no cases \\
\hline & & Ambivalence, not solved & & cases $1,4,6,8$ \\
\hline
\end{tabular}

Based on 13 cases. The pattern in case 2 remained unclear

medication four more years", thus strengthening his long-term motivation.

\section{Pattern 2: Not ambivalent, no motivation for medication adherence}

This patient's process is characterized by dominating cognitions, through all MI-sessions, on reasons to stop medication (Table $6 \mathrm{~b}$ ). In one case a language barrier hindered the execution of MI, and the therapist and patient failed to engage with each other (case 7). In the other case (case 3, successful case) therapist and patient explored both the patient's motives to stop the medication as well as alternative perspectives on the benefits of medication. However, this conversation did not evoke new cognitions on medication. As a result, the patient held on to his decision to stop the medication as soon as possible.

\section{Pattern 3: Ambivalence solved, motivated for medication adherence}

In three cases (5, 13 and 14) the patients' cognitions switched during the MI-sessions from doubt and ambivalence to needing long-term use of medications because of their effects (Table 6c). In the cases 5 and 14 (successful cases), this happened after exploring both sides of the

Table 5 Successful and unsuccessful cases

\begin{tabular}{|c|c|c|c|c|c|c|}
\hline Criteria & $\begin{array}{l}\text { Serious and explicit } \\
\text { consideration of } \\
\text { motives }\end{array}$ & $\begin{array}{l}\text { Exploration of } \\
\text { ambivalence and/ } \\
\text { or potential barriers }\end{array}$ & $\begin{array}{l}\text { Explicit discussion } \\
\text { of values and goals } \\
\text { in relation to } \mathrm{MA}^{\mathrm{a}}\end{array}$ & $\begin{array}{l}\text { Ambivalence was } \\
\text { solved and/or action } \\
\text { plan was made }\end{array}$ & $\begin{array}{l}\text { Strengthening of } \\
\text { long-term motivation }\end{array}$ & $\begin{array}{l}\text { Decision based on } \\
\text { intrinsic motivation }\end{array}$ \\
\hline \multicolumn{7}{|c|}{ Cases with ambivalence at baseline } \\
\hline 1 & + & - & - & - & & + \\
\hline 4 & + & - & - & - & & - \\
\hline 5 & + & + & + & + & & + \\
\hline 6 & + & - & - & - & & - \\
\hline 8 & + & - & - & - & & - \\
\hline 13 & + & - & - & + & & - \\
\hline 14 & + & + & + & + & & + \\
\hline \multicolumn{7}{|c|}{ Cases without ambivalent at baseline, motivated for MA } \\
\hline 9 & + & $-b$ & - & & - & - \\
\hline 10 & + & $+^{b}$ & + & & + & + \\
\hline 11 & - & $-\mathrm{b}$ & - & & - & - \\
\hline 12 & + & $-\mathrm{b}$ & - & & - & - \\
\hline \multicolumn{7}{|c|}{ Cases without ambivalence at baseline, no motivation for MA } \\
\hline 3 & + & & + & & & + \\
\hline 7 & - & & - & & & - \\
\hline \multicolumn{7}{|c|}{ Case in which the client avoided a serious conversation on MA } \\
\hline 2 & - & - & - & - & - & - \\
\hline
\end{tabular}


Table 6 Examples of courses of cognitions on medication through the sessions ${ }^{a}$

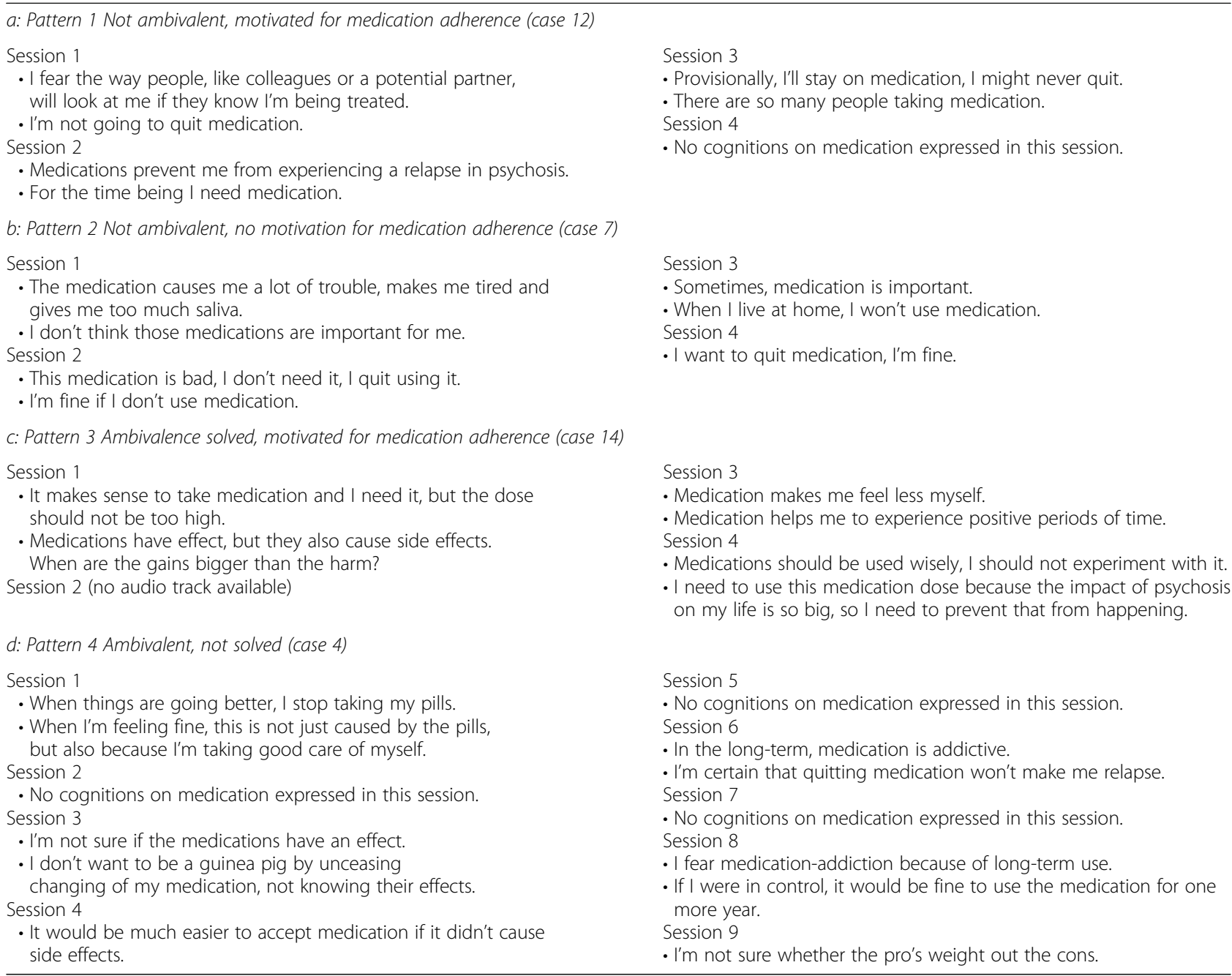

${ }^{a}$ Cognitions are explicitly or implicitly expressed by the patient. Sessions may have contained more cognitions, for reasons of space limitation we used maximal two cognitions per session

ambivalence. Guided by the therapists' open-ended questions and complex reflections, these patients discovered the relations between medication adherence, indirect benefits of medication and of relapse prevention, and important goals and values for them. This seemed to be key for the patients in solving their ambivalence. One patient saw medication as a strong protector against psychosis, but she felt that medication influenced her emotions, feeling "a little muted" and "not feeling completely myself". However, "Keeping my job" and "Autonomy" were important values for her, as she wanted to stay in control, and so she employed a self-developed minimal dosing strategy. But sometimes the dose was too low, resulting in a relapse. Through the sessions this ambivalence shifted to "If I use an optimal dose keeping me stable, and helping me to function well in my job, I can learn to accept that I am a little muted and a little slower." (case 5).
In case 13, during the last session, the patient also switches his cognitions from 'doubt/ambivalence' to 'needing medication for its effect'. But this switch had not been preceded by an exploration of the ambivalence by the patient, nor was medication linked to the patient's values. Hence, the base of intrinsic motivation for this patient's decision to adherence is unclear.

\section{Pattern 4: Ambivalent, not solved}

These four patients (cases 1, 4, 6 and 8) expressed cognitions showing doubt and ambivalence (Table 6d). In two cases (cases 4 and 8 ) the patient and therapist did not succeed in building a trusting relationship, and their conversations remained superficial. Both patients accepted the present need to take medication because external factors (the treating physician; being subjected to compulsory treatment) demand this. But they also set a one year limit 
as an acceptable period of time for medication use, with the intention to stop.

In all four cases the patient process stagnated after expressing the ambivalence towards, or barriers for, longterm medication use. The therapist and the patient kept going around in circles about the pros and the cons, and were not able to explore and solve the ambivalence.

\section{Successful/unsuccessful}

In the first session of all cases the therapist made an effort to engage with the patient, mostly by asking the patient to review his/her illness history and his/her experiences in mental health care. A trusting relationship is the base of motivational interviewing, and therefore a prerequisite for success. In all four successful cases (3, 5, 10 and 14) and in five of the nine unsuccessful cases $(1,6,9,12$ and 13), the MISC-rating of patient selfexploration was $\geq 4$, indicating a trusting relationship. In the four cases (4, 7, 8 and 11) lacking such engagement, the conversation remained superficial, with limited openness shown by the patient. One patient expressed this during the last session in a closing remark: "I know what you're thinking and what you want to say. I will not argue over that, but I have my own vision and opinion." (case 4). In line with MI-theory, the trusting relationship was fostered if the therapist showed good listening skills, asked open-ended questions, reflected the patient's experiences and perceptions and showed empathy, acceptance and understanding. By contrast, the relationship between patient and therapist was hindered by the therapist focusing on the actual facts in the patient's story (ignoring the patient's perception), and taking up the expert-role. Moreover, the emergence of a strict question-answer pattern, or the existence of a language barrier between patient and therapist, also impeded this relationship.

In successful cases the patients had the opportunity to tell their story from their perspective and without rushing. This story included ambivalence or potential barriers to long-term medication use, and the patients became aware of their ambivalences. The therapists and patients explored both sides of the ambivalence, and the patients linked medication use to their own goals and values. Hereafter the patients articulated their intention to adhere, based on their previously explored motives. In the unsuccessful cases, although articulated by the patient, ambivalences or barriers remained unexplored. In most of the unsuccessful cases the patients expressed their values, but the therapists missed opportunities to elicit change talk by linking these goals or values to medication adherence (Table 7). One patient expressed his fear of relapse and hospitalization: "I don't ever want to go back there", the therapist then only reflected this goal, failing to query how medication might contribute to this (case 8).

\section{Medication adherence}

One of the main outcomes on medication adherence after six months in the originating RCT [9] was a 5-point adherence item of the Life Chart Schedule (LCS) [20], judged by patient, physician and/or caregiver. This followup score was complete for six patients. The scores indicate, in accordance with their patient process, $\geq 4$ for patients who decided to adhere to long-term medication. An exception is the ambivalent patient in case 1, with a higher score than expected (Table 8).

\section{Discussion}

In this study, we found four patterns of the patient process of becoming (more) motivated for long-term medication adherence. We detected that the content and course of the expressed cognitions on medication may serve as a possible indicator for that process, and we identified three success factors.

The first success factor was the trusting relationship. The establishment of such a relationship promotes the depth of patient engagement. The second success factor was the therapist's ability to adapt the MI-strategy to the patient process. Through this strategy, the therapist stimulates the mechanisms of change within the patient [21]. One of these potential mechanisms is "change talk", as it results in the patient hearing him/herself argue for medication adherence [22]. By hearing him/herself articulating "I must take my pills, or else it will get me in trouble", the patient strengthens his/her belief in this cognition, and fosters a self-perception [23] of being "someone who takes medication for good reasons". In this study, we found that the lack of such a strategy in the unsuccessful cases appeared to hinder the progress of the patient process.

An explicit conversation regarding the patient's values or goals in relation to medication adherence was the third success factor. Taking medication is often associated with being ill and not feeling well, so intrinsic motivation for long-term medication use can only be elicited if the medication serves an important goal for the patient. This means that the therapist should support the patient to reflect on his/her goals and values and on his/her willingness and ability to change (i.e. take medications for a prolonged period of time) for these goals or values. In line with MI-theory, it is the patient who has to voice this relation, not the therapist.

The combination of these success factors may constitute good MI-practice on medication adherence in this patient group. Miller and Rollnick [13, 24] stress that, in MI, the intervention comprises both the relational and technical components, and that the active ingredients must be present. But the exact effects and active ingredients may differ between target groups [22]. These active ingredients however, are not well known and based on 
Table 7 Content of the Ml-sessions

\begin{tabular}{lll}
\hline Elements of the sessions & $\begin{array}{l}\text { Successful cases }(n=4) \\
\text { yes / no }\end{array}$ & $\begin{array}{l}\text { Unsuccessful cases }(n=9) \\
\text { yes / no }\end{array}$ \\
\hline Trusting relationship & $4 / 0$ & $5 / 4$ \\
Open conversation on medication adherence & $4 / 0$ & $5 / 4$ \\
Ambivalence or barriers articulated by the patient & $2 / 2$ & $7 / 2$ \\
Values or goals articulated by the patient & $4 / 0$ & $8 / 1$ \\
\hline
\end{tabular}

MI-theory, which was inductively derived from the analysis of clinical practice $[25,26]$, and on inconsistent findings from deductive empirical research [25]. In alcohol dependency studies, change talk and intention to change were related to better outcomes [21], while therapist MI-inconsistent behaviour was related to worse outcomes [21]. In a meta-analysis on the potential technical MI-key components [27], MI-consistent skills were associated with more change talk, and MI-inconsistent skills with less change talk and more sustain talk. In a secondary analysis of two RCT's on brief MI in college students [28], client self-exploration and therapist MISpirit were associated with better outcomes. In research with mixed mental health groups [29], patient engagement was found as a potential mechanism of change. So, all these studies suggest potential active ingredients that are in line with MI-theory. We found that MI-Spirit and patient engagement constituted the basis of a fruitful MI-session. Empathy, partnership and acceptance and the technical MI-strategy were essential components in the successful cases. Lane [30] and Hilton et al. [25] however, point out that the focus on theorized ingredients may be premature, and call for qualitative inductive research for a deeper understanding of the phenomenon of MI and processes within MI. In our qualitative study, we found three success factors, and two of them, "a trusting relationship" and "the therapist's ability to adapt the MI-strategy to the patient process", refer to MI-skills that, in line with MI-theory, are standard elements of all MI [24]. The third success factor "exploring values" is an optional MI-component, and our study suggests that this optional component may be a key component of MI in this patient group with medication adherence as the target behaviour.

Our study adds to the scarce research literature on MI to enhance medication adherence in patients with schizophrenia. Drymalski and Campbell [31] conclude in their review that, due to serious methodological concerns, there is no reliable research on $\mathrm{MI}$ and medication adherence in patients with schizophrenia before 2006. In the trial from which the present sample originates, Barkhof et al. [9] found no effect of MI on medication adherence, but there were indications that targeted use of MI might be beneficial for medication adherence for some subgroups. In the present study, however, we used other criteria to detect successful cases, i.e. not medication adherence per se, but a patient decision (not) to adhere, based on intrinsic motivation after explicit exploration of motives, goals,

Table 8 Medication adherence at 6-month follow-up

\begin{tabular}{|c|c|c|c|c|c|c|}
\hline Baseline & Patient process & & $\begin{array}{l}\text { Observed cases } \\
(n=13)\end{array}$ & $\begin{array}{l}\text { LCS-score } \\
\text { patient }^{\mathrm{a}}\end{array}$ & $\begin{array}{l}\text { LCS-score } \\
\text { physician }^{a}\end{array}$ & $\begin{array}{l}\text { LCS-score } \\
\text { carer }^{\text {a }}\end{array}$ \\
\hline \multirow[t]{6}{*}{ Not-ambivalent } & Remained not-ambivalent & Motivation for medication adherence & case 9 & 4 & - & - \\
\hline & & & case 10 & - & - & - \\
\hline & & & case 11 & 5 & 5 & 5 \\
\hline & & & case 12 & 4 & 5 & 5 \\
\hline & & No motivation for medication adherence & case 3 & - & - & - \\
\hline & & & case 7 & - & - & - \\
\hline \multirow[t]{7}{*}{ Ambivalent } & Ambivalence, solved & Motivation for medication adherence & case 5 & 5 & - & 5 \\
\hline & & & case 13 & - & - & - \\
\hline & & & case 14 & - & - & - \\
\hline & Ambivalence, not solved & Ambivalent on medication adherence & case 1 & 4 & 4 & - \\
\hline & & & case 4 & - & - & - \\
\hline & & & case 6 & 3 & 2 & 2 \\
\hline & & & case 8 & - & - & - \\
\hline
\end{tabular}


values, and solved ambivalence and potential barriers. As a consequence, one case in which the patient decided not to adhere to long-term medication use, is also a successful case (case 3).

\section{Strengths and limitations of this study}

A strength of this study is the pragmatic character of the original RCT. After a 32-h training and with monthly supervision, the therapists started the MI-intervention. This closely parallels usual practice in non-research conditions. Hence, the results reflect the MI-practice of newly starting MI-therapists at beginning proficiency, and not of experienced MI-therapists at expert level. This is also a limitation, because it may have led to less variation in patient process patterns, and it may explain why none of the initially not-ambivalent patients became ambivalent during the MI-intervention. Another strength is the inclusion of patients with a severe course of schizophrenia who experienced a psychotic relapse due to medication nonadherence in the past year.

A limitation of this study was the size and the composition of the sample. We retrieved sufficient audio-recorded MI-sessions for 14 of the 55 patients. This led to a selection of patients from the original sample, so this study lacks an analysis of patients not-consenting to audio-recording, and of drop-out patients.

The qualitative design and the limitations in sample size and sample composition call for prudence in generalization of the findings. Many factors influence the patient process, e.g. patient factors like education level and type and severity of mental illness, therapist factors like experience, but also health care related factors such as length of time available for the MI-sessions. We studied 14 specific cases, which enabled us to gain a more profound insight in what happened in these MI-sessions. However, this does not mean these sessions represent all patient situations, so this limits the generalization of our findings. Despite these limitations, our study results offer an indication on processes that might also be important in MI-sessions with comparable patients with multi-episode schizophrenia and recent medication nonadherence in their history.

\section{Conclusions}

First, there are different patterns of patient processes in MI on medication adherence. This suggests that motivation for medication adherence may be improved if MItherapists adapt their MI-strategy to the process. An indicator of these processes may be found in the course of the expressed cognitions on medication.

Second, criteria based on both MI-theory and good practice of care may be useful to differentiate between successful and unsuccessful cases. Third, the findings in our study suggest that the content of a successful MI-intervention for this target behaviour comprises a trusting relationship, the articulation of ambivalence or possible barriers for sustained medication use and the exploration of this ambivalence and barriers in relation with patient values and goals. When a patient is not ambivalent, MI may support the exploration of medication adherence in relation to the patient's values and goals, to strengthen long-term motivation, or to explore the possibility of new patient perspectives on indirect benefits of long-term medication use.

\section{Abbreviations \\ DSM-IV: Diagnostic and Statistical Manual of Mental Disorders4th Edition; LCS: Life Chart Score; MA: Medication adherence; MI: Motivational Interviewing; MISC: Motivational Interviewing Skill Code; MITI: Motivational Interviewing Treatment Integrity; n.a.: not applicable; RCT: Randomized Controlled Trial; RR: Risk Ratio; SCOPE: Motivational Interviewing Sequential Code for Observing Process Exchanges; USA: United States of America}

\section{Acknowledgements}

We thank Vera Kruse for her help in coding and for independently (double) analysing two cases, Elena Le Poole for her help in coding, and Grace Jenkins for her comments on our English language use.

Funding

This work was supported by a research grant from the Netherlands Organisation for Scientific Research (NWO) to JD.

\section{Availability of data and materials}

The datasets generated and analysed during the current study are not publicly available due to identifying participant information. Data may be available from the corresponding author upon request, but restrictions apply on the availability of these data in accordance with the ethical rules of the Medical Ethical Committee of the Academic Medical Center of the University of Amsterdam.

\section{Authors' contributions}

$J D, C L, L d H, W S o R, R P, E B, B v M$ contributed to the study design. JD and EB performed the data acquisition and the data analysis. JD, LdH and EB interpreted the data, and $C L$ and BvM checked the data-interpretation. JD, $C L, L d H, W S o R, R P, E B, B v M$ participated in the writing of the manuscript. All authors read and approved the final manuscript.

Ethics approval and consent to participate

This study was approved by the Medical Ethics Committee of the Academic Medical Center, Amsterdam. Written informed consent was obtained from all participants.

\section{Competing interests}

The authors declare that they have no competing interests.

\section{Publisher's Note}

Springer Nature remains neutral with regard to jurisdictional claims in published maps and institutional affiliations.

\section{Author details}

${ }^{1}$ ACHIEVE Centre of Applied Research, Faculty of Health, Amsterdam University of Applied Sciences, Tafelbergweg 51, 1105 BD Amsterdam, The Netherlands. ${ }^{2}$ Department of Psychiatry, Academic Medical Center, University of Amsterdam, Meibergdreef 9, 1105 AZ Amsterdam, The Netherlands.

${ }^{3}$ Department of Cardiology, Academic Medical Center, University of Amsterdam, Meibergdreef 9, 1105 AZ Amsterdam, The Netherlands. ${ }^{4} G G Z$ Rivierduinen, Sandifortdreef 19, 2333 ZZ Leiden, The Netherlands. ${ }^{5}$ Inholland University of Applied Sciences, De Boelelaan 1109, 1081 HV Amsterdam, The Netherlands. ${ }^{6}$ Department of Psychiatry, VU University Medical Center, De Boelelaan 1117, 1081 HV Amsterdam, The Netherlands. ${ }^{7}$ Parnassia Psychiatric Institute, Monterseweg 93, 2553 RJ The Hague, The Netherlands. 
Received: 29 May 2017 Accepted: 4 May 2018

Published online: 18 May 2018

\section{References}

1. Lieberman JA, Stroup TS, McEvoy JP, Swartz MS, Rosenheck RA, Perkins DO, et al. Effectiveness of antipsychotic drugs in patients with chronic schizophrenia. N Engl J Med. 2005:353:1209-23.

2. Leucht S, Tardy M, Komossa K, Heres S, Kissling W, Salanti G, et al. Antipsychotic drugs versus placebo for relapse prevention in schizophrenia: a systematic review and meta-analysis. Lancet. 2012;379:2063-71.

3. Higashi K, Medic G, Littlewood K, Diez T, Granström O, De Hert M. Medication adherence in schizophrenia: factors influencing adherence and consequences of nonadherence, a systematic literature review. Ther Adv Psychopharmacol. 2013;3:200-18.

4. Burke B, Arkowitz $H$, Menchola M. The efficacy of motivational interviewing: a meta-analysis of controlled clinical trials. J Consult Clin Psychol. 2003;71:843-61.

5. Hettema J, Steele J, Miller W. Motivational interviewing. Annu Rev Clin Psychol. 2005;1:91-111.

6. Lundahl B, Burke B. The effectiveness and applicability of motivational interviewing: a practice-friendly review of four meta-analyses. J Clin Psychol. 2009:65:1232-45.

7. Lundahl B, Moleni T, Burke BL, Butters R, Tollefson D, Butler C, et al. Motivational interviewing in medical care settings: a systematic review and meta-analysis of randomized controlled trials. Patient Educ Couns. 2013:93:157-68.

8. Rubak S, Sandbaek A, Lauritzen T, Christensen B. Motivational interviewing: a systematic review and meta-analysis. Br J Gen Pract. 2005;55:305-12.

9. Barkhof E, Meijer CJ, Sonneville LJ, Linszen DH, De Haan L. The effect of motivational interviewing on medication adherence and hospitalization rates in non-adherent patients with multi-episode schizophrenia. Schizophr Bull. 2013;39:1242-51.

10. Kemp R, Hayward P, Applewhaite G, Everitt B, David A. Compliance therapy in psychotic patients: randomised controlled trial. BMJ. 1996;312:345-9.

11. Kemp R, Kirov G, Everitt B, Hayward P, David A. Randomised controlled trial of compliance therapy. 18-month follow-up. Br J Psychiatry. 1998;172:413-9.

12. O'Donnell C, Donohoe G, Sharkey L, Owens N, Migone M, Harries R, et al. Compliance therapy: a randomised controlled trial in schizophrenia. BMJ. 2003;327:834.

13. Miller WR, Rollnick S. Motivational interviewing: helping people change. 3rd ed. New York: Guilford Press; 2013.

14. Miller WR, Rollnick S. Motivational interviewing: preparing people for change. 2nd ed. New York: Guilford Press; 2002.

15. Stake RE. Multiple case study analysis. New York: Guilford Press; 2006.

16. Martin T, Moyers TB, Houck J, Christopher P, Miller WR. Motivational Interviewing Sequential Code for Observing Process Exchanges (SCOPE). Coder's manual. 2005. http://casaa.unm.edu/download/scope.pdf Accessed 28 March 2013

17. Miller WR, Moyers TB, Ernst D, Amrhein P. Manual for the Motivational Interviewing Skill Code (MISC). Version 2.1. 2008. http://casaa.unm.edu/ download/misc.pdf Accessed 27 October 2013.

18. Moyers TB, Martin T, Manuel JK, Miller WR, Ernst D. Manual for the Motivational Interviewing Treatment Integrity (MITI). Version 3.1.1. 2010. http://casaa.unm.edu/download/MIT13_1.pdf Accessed 17 August 2016.

19. Kaplan JE, Keeley RD, Engel M, Emsermann C, Brody D. Aspects of patient and clinician language predict adherence to antidepressant medication. J Am Board Fam Med. 2013;26:409-20.

20. Susser E, Finnerty M, Mojtabai R, Yale S, Conover S, Goetz R, et al. Reliability of the life chart schedule for assessment of the long term course of schizophrenia. Schizophr Res. 2000;42:67-77.

21. Apodaca TR, Longabaugh R. Mechanisms of change in motivational interviewing: a review and preliminary evaluation of the evidence. Addiction. 2009;104:705-15.

22. Miller WR, Rose GS. Toward a theory of motivational interviewing. Am Psychol. 2009;64:859-69.

23. Bem DJ. Self-perception: an alternative interpretation of cognitive dissonance phenomena. Psychol Rev. 1967;74:183-200.

24. Miller WR, Rollnick S. The effectiveness and ineffectiveness of complex behavioral interventions: impacts of treatment fidelity. Contem Clin Trials. 2014;37:234-41.
25. Hilton $\mathrm{CE}$, Lane $\mathrm{C}$, Johnston $\mathrm{LH}$. Has motivational interviewing fallen into its own premature focus trap? Int J Adv Counseling. 2016;38:145-58.

26. Miller WR. Motivational interviewing with problem drinkers. Behav Cogn Psychother. 1983:11:147-72.

27. Magill M, Gaume J, Apodaca TR, Walthers J, Mastroleo NR, Borsari B, et al. The technical hypothesis of motivational interviewing: a meta-analysis of Ml's key causal model. J Clin Psychol. 2014;82:973-83.

28. Borsari B, Apodaca TR, Jackson KM, Mastroleo NR, Magill M, Barnett NP, et al. In-session processes of brief motivational interviewing interventions in two trials with mandated college students. J Consult Clin Psychol. 2015;83:56-67.

29. Romano M, Peters L. Evaluating the mechanisms of change in motivational interviewing in the treatment of mental health problems: a review and meta-analysis. Clin Psychol Rev. 2015;38:1-12.

30. Lane C. A discourse analysis of client and practitioner talk during motivational interviewing sessions. ClinPsyD Thesis (Volume 1). University of Birmingham. 2012. http://etheses.bham.ac.uk/3708/1/Lane12ClinPsyD1.pdf Accessed 16 June 2016.

31. Drymalski WM, Campbell TC. A review of motivational interviewing to enhance adherence to antipsychotic medication in patients with schizophrenia: evidence and recommendations. J Ment Health. 2009;18:6-15.

\section{Ready to submit your research? Choose BMC and benefit from:}

- fast, convenient online submission

- thorough peer review by experienced researchers in your field

- rapid publication on acceptance

- support for research data, including large and complex data types

- gold Open Access which fosters wider collaboration and increased citations

- maximum visibility for your research: over $100 \mathrm{M}$ website views per year

At BMC, research is always in progress.

Learn more biomedcentral.com/submissions 